\title{
Analysis on the Effect of Metacognition Intervention Combined with Group Psychological Counseling on College Students' Depression Psychology
}

\author{
Rong Zhen \\ Faculty of Humanities \\ Jiangxi University of Traditional Chinese Medicine \\ Nanchang, China
}

\author{
Huajie Sui \\ Faculty of Humanities \\ Jiangxi University of Traditional Chinese Medicine \\ Nanchang, China
}

\author{
Yan Liu* \\ Faculty of Humanities \\ Jiangxi University of Traditional Chinese Medicine \\ Nanchang, China
}

\begin{abstract}
To explore the effect of meta-recognition intervention combined with group psychological counseling on depression in college students, 200 college students with depression were randomly divided into study group $(n=100)$ and control group $(n=100)$, and the control group was treated with meta-recognitive intervention. The scores of HAMD (15.02-4.16), BDI (8.09-3.58) and DAS (125.16-6.42) after the intervention of the study group were significantly lower than those of the control group $(P<0.05)$. The positive response score $(25.23-3.72)$ after the study group was significantly higher than that of the control group, while the negative response score $(8.92-1.13)$ was significantly lower than that of the control group. The difference between the two groups was statistically significant $(P<0.05)$. So we can reach the conclusion that the combination of metacognitive intervention and group psychological counseling can reduce the depression mood of college students and improve their coping style and psychological intervention.
\end{abstract}

Keywords-college students; depression; metacognitive intervention; group psychological counseling; intervention effect

\section{INTRODUCTION}

Depression is an individual's common psychological disorder, which has an obstacle to the individual's psychological adaptation. Most college students face interpersonal problems, academic problems, economic pressure, life environment change, etc., meanwhile the psychological state of college students is not mature enough to sustain depression [1]. According to the investigation, the incidence of depression in Chinese college students is $12.86 \%$ [2]. Depression has a serious negative effect on the life and learning of college students, sometimes even a suicidal idea arises [3]. Therefore, this paper aims at discussing the effect of metacognitive intervention on the psychological intervention of college students' depression, and providing guidance and management for the depression mood of the college students.
On the basis of study background above, we conducted this analysis on the effect of metacognition intervention combined with group psychological counseling on college students' depression psychology, which can show us obvious comparison results.

\section{METHODS}

With the approval of the Medical Ethics Committee, 200 depressed college students from a college of science and technology were randomly divided into study group $(\mathrm{n} \leq 100)$ and control group $(\mathrm{n}=100)$. Criteria include: (1) BDI score $\geq$ 5, HAMD $\geq 7$; (2) a strong willingness to change themselves; (3) participate in voluntarily and agree to sign an information letter. The excluded marks are as follows: (1) patients with communication disorders; (2) patients with mental system diseases; (3) patients with severe physical diseases; (4) those who quit halfway. In the study group, 46 cases were female, 54 cases were male, ages were from 16 to 23 (17.89 \pm 1.24$)$ years old. In the control group, there were 43 females and 56 males, aged from 16 to $22(17.93 \pm 1.47)$ years old. There was no significant difference in the basic data between the two groups, and the equilibrium was comparable $(\mathrm{P}>0.05)$.

The control group was given metacognition intervention method. The psychological teacher explained the metacognition strategy method to the students, and input the accurate thinking as well as the behavior procedure through the positive strengthening and the long-term self-training, which could cause the university students to transfer the behavior training results into their personality and instruct them to record their own emotional change, experience the physical change under the positive and negative emotion. This method requires college students to carry on the aerobic training every day. By deep breathing training, progressive muscle relaxation and other training, these college students check and record 


\begin{tabular}{|c|c|c|c|c|}
\hline \multicolumn{5}{|c|}{ Cont. to TABLE I. } \\
\hline & $\begin{array}{c}\text { After } \\
\text { intervention }\end{array}$ & $19.86 \pm 4.75$ & $12.79 \pm 4.30$ & $145.53 \pm 7.75$ \\
\hline$t$ & & 7.299 & 13.334 & 4.239 \\
\hline$P$ & & 0.000 & 0.000 & 0.000 \\
\hline \multicolumn{5}{|c|}{ * Comparison between groups, $\mathrm{P}<0.05}$.
\end{tabular}

Based on this, the study group divided these college students into 10 intervention teams, each team contains 10 persons, team psychological counseling was divided into 5 stages, once a week, 5 times in total. The first stage: the theme is mutual understanding, the goal is to understand the results and significance of psychological counseling in the team more quickly, to help the team members understand each other. The interactive content is interpersonal interaction snowball. The second stage: the theme is to open up and explore themselves. The goal is to help understand their inner state, objective evaluation and understanding of themselves, and help to explore the outlook in life and value linked with the content of personal self-portrait. it therapy. The third stage: the theme is understanding the team, the goal is to understand the persons' thoughts to improve the interpersonal interaction and the content is the sandbox game. The fourth stage: the theme is to interpret the mood and resolve the pressure, the goal is to understand the mood and pressure and grasp the imagination desensitization method, the content is the music relaxation method. The fifth stage: The theme is my future is not a dream, the goal is to explore the career and set up the personal goal, the content is the career discussion.

The observation index includes BDI, HAMD, and DAS, which were used to assess the status of depression before and after the intervention of two groups of patients, and the score was proportional to the degree of depression [4]. A simple coping style questionnaire (SCSQ) was used to evaluate the coping styles before and after the intervention of the two groups, including positive response and negative response to 2 dimensions, 20 entries, and the higher the score, the greater the tendency of the coping style will be [5].

\section{STATISTICAL DATA ANALYSIS}

Use SPSS 25.0 to calculate the data results, "\%" represents the counting data, use $\mathrm{x} 2$ test, " $\pm S$ " represents the measurement data. $T$ test was used to indicate the data difference $(\mathrm{P}<0.05)$.

\section{A. Comparison of Depressive State between the Two Groups before and after Intervention}

The scores of HAMD (15.02-4.16), BDI (8.09-3.58) and DAS (125.16-6.42) after intervention of the study group were significantly lower than that of the control group $(\mathrm{P}<0.05)$. See Table 1.

TABLE I. COMPARISON OF THE DEPRESSIVE STATES BEFORE AND AFTER THE INTERVENTION OF THE TWO GROUPS (\% S, MIN)

\begin{tabular}{|c|c|c|c|c|}
\hline Group & Time & HAMD & BDI & DAS \\
\hline \multirow{2}{*}{$\begin{array}{c}\text { Research } \\
\text { group }\end{array}$} & $\begin{array}{c}\text { before } \\
\text { intervention }\end{array}$ & $26.01 \pm 7.24$ & $16.57 \pm 6.22$ & $167.29 \pm 10.92$ \\
\cline { 2 - 5 } & $\begin{array}{c}\text { After } \\
\text { intervention }\end{array}$ & $15.02 \pm 4.16^{*}$ & $8.09 \pm 3.58^{*}$ & $125.16 \pm 6.42^{*}$ \\
\hline$t$ & & 13.162 & 22.963 & 9.576 \\
\hline$P$ & 0.000 & 0.000 & 0.000 \\
\hline $\begin{array}{c}\text { Control } \\
\text { group }\end{array}$ & $\begin{array}{c}\text { before } \\
\text { intervention }\end{array}$ & $26.57 \pm 7.71$ & $16.62 \pm 6.89$ & $168.11 \pm 13.45$ \\
\hline
\end{tabular}

\section{B. Comparison between the Two Groups of Intervention before and after Intervention}

The positive response score (25.23-3.72) after the study group was significantly higher than that of the control group, and the negative response score (8.92-1.13) was significantly lower than that of the control group. The difference between the two groups was statistically significant $(\mathrm{P}<0.05)$. See Table 2.

TABLE II. COMPARISON OF THE RESPONSES BEFORE AND AFTER THE TWO GROUPS OF INTERVENTION (POINTS S, POINTS)

\begin{tabular}{|c|c|c|c|}
\hline Group & Time & Coping with & Negative coping \\
\hline \multirow{2}{*}{ Research group } & before intervention & $18.96 \pm 2.58$ & $13.76 \pm 1.41$ \\
\cline { 2 - 4 } & after intervention & $25.23 \pm 3.72^{*}$ & $8.92 \pm 1.13^{*}$ \\
\hline$t$ & & 13.850 & 26.693 \\
\hline$P$ & & 0.000 & 0.000 \\
\hline Control group & before intervention & $18.80 \pm 2.73$ & $13.69 \pm 1.35$ \\
\hline & after intervention & $21.75 \pm 3.11$ & $11.20 \pm 1.20$ \\
\hline$t$ & & 7.129 & 13.785 \\
\hline$P$ & & 0.000 & 0.000 \\
\hline
\end{tabular}

\section{RESUlts}

Depression is the main cause of college students' extreme behaviors like suicide, etc. Therefore, how to improve the psychological state of college students and reduce depression is the main focus of psychological teachers in colleges and universities at present. Group psychological counseling is to guide college students to discuss through setting up situations and problems, help them re-understand themselves in activities, produce the spiritual motive force of psychological and behavioral change, help them develop and improve themselves and shape mature personality [6]. Metacognition intervention is based on psychological counseling, aiming at helping college students to self-perception, reflection, supervision and control of their subconscious and other psychological activities. Metacognition is the system of practical operation includes the basic skills of psychological consultation, the hypnosis, the relaxation of the clinical operation technology and so on. It is necessary to practice the theory on its own as well as the visitors. It is also necessary to continuously promote the practice thought to the theory, so that the practical operation wisdom can be truly grasped.

In the meta-cognitive intervention, students should first observe which behaviors are subconscious behaviors, whether they can solve their bad behavior habits and consciously use this set of theories to explain their cognition, emotional feelings, thinking behavior and so on. The results of this study reveal that the HAMD, BDI, DAS scores of the study group were significantly lower than those of the control group after intervention $(\mathrm{P}<0.05)$. After intervention, the positive coping score of the study group was significantly higher than that of 
the control group, while the negative coping score was significantly lower than that of the control group $(\mathrm{P}<0.05)$. The results indicate that metacognition intervention combined with group psychological counseling intervention can provide explanations, comfort and drum for college students. In order to improve the psychological state of the patient, the negative response is replaced with positive response [7].

\section{CONCLUSIONS}

According to the investigation study and statistical analysis results above, we can reach the conclusions that metacognitive intervention and group psychological counseling can effectively reduce the depression mood of college students and improve their coping style. Actually, the psychological intervention effect is prominent, which will be quite worthy to popularize.

\section{REFERENCES}

[1] L. Xin and Y. Zhu, "A study on the effect of group psychological counseling on the psychological adaptability of freshmen," Psychological Monthly, vol. 14, no. 16, p. 49, 2019. (In Chinese)
[2] F. Peng and M. Li, “An analysis of the effect of metacognition group intervention on self-efficacy, coping style and social support of ethnic freshmen in higher vocational education," China's Out-of-School Education, no. 27, pp. 71-73, 2017. (In Chinese)

[3] L. H. Xiong, Y.M. Li, Y. Gao, and R. Yan, "A study on the effect of dynamic-oriented group psychotherapy on depression in college students," Chinese Medical Innovation, vol. 14, no. 20, pp. 137-141, 2017. (In Chinese)

[4] W. P. Dmowski, M. Pry, J. Ding, and N. Rana, "Cycle-specific and cumulative fecundity in patients with endometriosis who are undergoing controlled ovarian hyperstimulation-intrauterine insemination or in vitro fertilization-embryo transfer,” Fertil. Steril., vol. 78, no. 4, pp. 750-756, 2002.

[5] J. J. Zhang, H. Y. Zhang, And R. Y. Yu, “A study on the intervention of Group Psychological Counseling on depressive symptoms of College students: based on the theoretical perspective of Positive Psychology,” Modernization of Education, vol. 3, no. 16, pp. 118-1191, 2016. (In Chinese)

[6] C. Nezhat, F. R. Nezhat, A. M. Siegler, A. A. Luciano, C. Nezhat, and D. S. Seldman, Operative gynecologic laparoscopy: principles and techniques. New York, NY: Camran Nezhat, 2000.

[7] A. Pan and Y. Z. Xie, "A study of the effect of the metacognitive intervention on depression of college students by group psychological counseling,” Journal of Kaili College, vol. 33, no. 4, pp. 135-137, 2015. (In Chinese) 